Section Editor

John J. Millichap, MD

Daniel A. Freedman, DO

Dara V.F. Albert, DO

Correspondence to

Dr. Freedman:

daniel.freedman@

nationwidechildrens.org

\title{
Opinion and Special Articles: \\ Neurology education at US osteopathic medical schools
}

ABSTRACT

Osteopathic medical schools have a longstanding tradition of training primary care physicians (PCP). Neurologic symptoms are common in the PCP's office and there is an undersupply of neurologists in the United States. It is therefore crucial for osteopathic medical students to have a strong foundation in clinical neurology. Despite the importance, a mere 6\% of osteopathic medical schools have required neurology clerkships. Furthermore, exposure to neurology in medical school through required clerkships has been correlated with matching into neurology residency. As osteopathic medical schools continue to expand, it will become increasingly important to emphasize the American Academy Neurology's published guidelines for a core clerkship curriculum. Practicing neurologists should take an active role in encouraging osteopathic medical schools to adopt these guidelines. Neurology ${ }^{\circledast}$ 2017;89:e282-e283

\section{GLOSSARY}

AAN = American Academy of Neurology

One of the pillars of osteopathic medical education is the long-standing tradition of training primary care physicians. The majority of osteopathic medical schools clearly emphasize this in their mission statements. Furthermore, osteopathic medical schools strategically position themselves in rural and underserved regions, forging a commitment to train physicians who will serve those communities. ${ }^{1,2}$ It is estimated that by 2019, a quarter of US medical school graduates will be from osteopathic medical schools. ${ }^{3}$

Neurologic problems are common and will be routinely encountered by all primary care physicians. Approximately $10 \%-20 \%$ of patients seen in the primary care setting and up to $20 \%$ of hospitalized patients may have neurologic symptoms. ${ }^{4}$ The American Academy of Neurology (AAN) estimates that there is an $11 \%$ shortfall in the total neurology workforce and this is projected to continue to worsen to $19 \%$ by $2025 . .^{5}$ Despite this great need, only $2.2 \%$ of US medical school graduates matched into neurology or child neurology through the National Resident Matching Program in 2017, with $10 \%$ of these matched graduates coming from osteopathic medical schools. ${ }^{6}$ Therefore, primary care physicians are not only likely to be the first physician encountered by a patient with a neurologic concern, but may be the only one. This is especially true when considering osteopathic physicians practicing in rural and underserved regions of the country, where access to neurologists will likely be sparse. Consequently, all physicians and particularly primary care physicians need to have some level of competence in approaching these patients.

Neurology is often cited as one of the most feared and most difficult specialties in medicine, a phenomenon coined over 2 decades ago as neurophobia. ${ }^{7}$ The presence of neurophobia has been demonstrated among medical students in the United States and abroad in various studies. Proposed etiologies for this phobia are limited exposure to clinical neurosciences, insufficient or poor teaching, diagnostic complexity of the specialty, and the difficulties inherent in the neurologic examination. ${ }^{7}$ This fear may lead to a discomfort in approaching patients with neurologic concerns and in turn may ultimately lead to suboptimal patient care. Basic psychology teaches us that confronting our fears through experiences helps ameliorate anxieties, in this case through clinical neurology exposure and education.

In 2002, the AAN published guidelines for a core curriculum in an attempt to define the "minimum body of clinical neurology skills and knowledge required of all graduating medical students." The consensus was that graduating medical students must know how to reliably perform a neurologic examination and that neurologists should be the ones to teach those skills to students. Their conclusion was for

From the Department of Pediatrics, Division of Neurology, Nationwide Children's Hospital/Ohio State University, Columbus.

Go to Neurology.org for full disclosures. Funding information and disclosures deemed relevant by the authors, if any, are provided at the end of the article. 
every medical school to require a minimum of 4 weeks of a clinical neurology clerkship that combines inpatient and outpatient experiences as well as time for didactic sessions. ${ }^{4}$ Despite these recommendations made over a decade ago, a mere $6 \%$ of osteopathic medical schools have required neurology clerkships. This is down from $10 \% 2$ years prior due to the creation of new osteopathic medical schools without required neurology clerkships. ${ }^{8,9}$ Consequently, most osteopathic physicians will graduate from medical school without ever having worked with a neurologist or examined a patient with a neurologic disorder alongside a neurologist, which may perpetuate neurophobia and the potential for lapses in medical acumen. Resource limitations of being in a rural or underserved area likely contribute to the difficulty of osteopathic medical schools having neurologists on faculty. This is likely another barrier to medical students participating in neurology clerkships. Osteopathic medical schools often overcome limitations regarding specialty faculty by requiring medical students to rotate at remote sites in other cities or states. In addition, community neurologists could take an active role in encouraging schools to adopt the AAN's guidelines and participate in educating students. Contributing to undergraduate osteopathic medical education not only rewards community neurologists with training future generations but also eases the burden of medical schools to find rotation sites. Osteopathic medical schools can foster community neurologists' involvement by offering teaching stipends or adjunct faculty appointments.

In addition to the need to train primary care osteopathic physicians with basic neurologic knowledge and skills, neurology education during medical school provides an opportunity to motivate future DOs to choose a career in neurology. Recent evidence suggests that the presence of a required neurology clerkship and ample opportunities for neurology electives are correlated with a higher likelihood of matching in neurology. ${ }^{8}$ Given the need for qualified neurologists in the United States, having access to a neurology clerkship provides an opportunity to inspire students to fill this niche and enter the field.

As osteopathic medical schools continue to expand and open new doors, it is imperative not to overlook the importance of training physicians to be competent in basic neurologic skills. Especially given the prevalence of neurologic disorders and the paucity of neurologists, primary care physicians need to be equipped with this knowledge. Emphasizing neurology in osteopathic medical education helps schools stay true to the central osteopathic credo of producing well-rounded physicians with a strong base in primary care medicine while embracing the AAN's guideline for undergraduate medical education in neurology. It may also help steer candidates towards pursuing a career in neurology.

\section{AUTHOR CONTRIBUTIONS}

Daniel Freedman: drafting/revising the manuscript, accepts responsibility for conduct of research and final approval. Dara Albert: drafting/revising the manuscript, study concept or design, analysis or interpretation of data, accepts responsibility for conduct of research and final approval.

\section{ACKNOWLEDGMENT}

The authors thank Dr. Rimas Lukas, Associate Co-Chief of the NeuroOncology Division, Associate Co-Director of the Brain Tumor Institute, Department of Neurology, Northwestern University Feinberg School of Medicine, for review of and comment on the manuscript prior to submission.

\section{STUDY FUNDING}

No targeted funding reported.

\section{DISCLOSURE}

The authors report no disclosures relevant to the manuscript. Go to Neurology.org for full disclosures.

\section{REFERENCES}

1. American Association of Colleges of Osteopathic Medicine. What is osteopathic medicine? Available at: aacom.org/ become-a-doctor/about-om. Accessed May 2, 2017.

2. Shannon SC, Teitelbaum HS. The status and future of osteopathic medical education in the United States. Acad Med 2009;84:707-711.

3. Gevitz N. The transformation of osteopathic medical education. Acad Med 2009;84:701-706.

4. Gelb DJ, Gunderson CH, Henry KA, Kirshner HS, Jósefowicz RF; Consortium of Neurology Clerkship Directors and the Undergraduate Education Subcommittee of the American Academy of Neurology. The neurology clerkship core curriculum. Neurology 2002;58:849-852.

5. Bradley WG. Neurology in the next two decades: report of the Workforce Task Force of the American Academy of Neurology. Neurology 2000;54:787-789.

6. National Residency Matching Program. Results and data: 2017 main residency match. Available at: nrmp.org/ match-data/main-residency-match-data/. Accessed June 20, 2017.

7. Jósefowicz RF. Neurophobia: the fear of neurology among medical students. Arch Neurol 1994;51:328-329.

8. Albert DV, Yin H, Amidei C, Dixit KS, Brorson JR, Lukas RV. Structure of neuroscience clerkships in medical schools and matching in neuromedicine. Neurology 2015; 85:172-176.

9. Ramos RL, Cuoco JA, Guercio E, Levitan T. Quantitative description of medical student interest in neurology and psychiatry. J Am Osteopath Assoc 2016;116:462-471. 


\section{Neurology}

\section{Opinion and Special Articles: Neurology education at US osteopathic medical schools Daniel A. Freedman and Dara V.F. Albert \\ Neurology 2017;89;e282-e283 \\ DOI 10.1212/WNL.0000000000004750}

This information is current as of December 11, 2017

\author{
Updated Information \& \\ Services
}

References

Subspecialty Collections

Permissions \& Licensing

Reprints including high resolution figures, can be found at: http://n.neurology.org/content/89/24/e282.full

This article cites 7 articles, 2 of which you can access for free at: http://n.neurology.org/content/89/24/e282.full\#ref-list-1

This article, along with others on similar topics, appears in the following collection(s):

Other Education

http://n.neurology.org/cgi/collection/other_education

Information about reproducing this article in parts (figures,tables) or in its entirety can be found online at:

http://www.neurology.org/about/about_the_journal\#permissions

Information about ordering reprints can be found online: http://n.neurology.org/subscribers/advertise

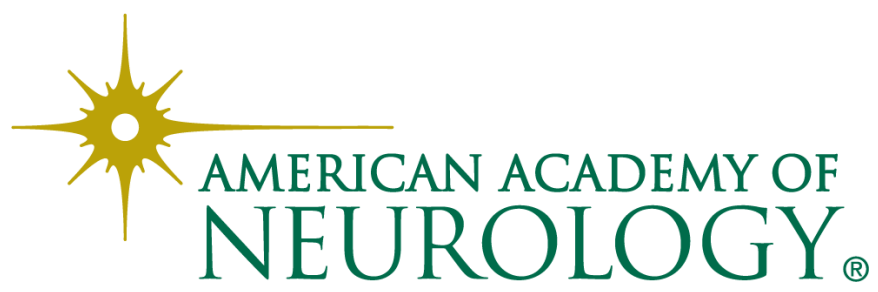

